\title{
Hepatocyte growth factor improves the survival of rats with pulmonary arterial hypertension via the amelioration of pulmonary hemodynamics
}

\author{
KIYOHISA HIRAMINE ${ }^{1}$, NAOYUKI SATA ${ }^{1}$, AKIO IDO $^{1}$, RYOZO KAMIMURA ${ }^{2}$, KENTARO SETOYAMA ${ }^{2}$, \\ KOU ARAI ${ }^{3}$, NORIHITO NURUKI ${ }^{1}$, YASUHIRO TANAKA ${ }^{1}$, HIROFUMI UTO ${ }^{1}$ and HIROHITO TSUBOUCHI ${ }^{1}$ \\ ${ }^{1}$ Digestive Disease and Life-Style Related Disease, Kagoshima University Graduate School of Medical and \\ Dental Sciences, Kagoshima; ${ }^{2}$ Frontier Science Research Center and ${ }^{3}$ Department of \\ Veterinary Clinical Science, Kagoshima University, Kagoshima, Japan
}

Received November 16, 2010; Accepted January 4, 2011

DOI: $10.3892 / \mathrm{ijmm} .2011 .616$

\begin{abstract}
Hepatocyte growth factor (HGF) is a multifunctional growth factor with mitogenic, anti-apoptotic and anti-fibrotic activities. In this study, we investigated the effect of administration of recombinant human HGF on pulmonary arterial hypertension. Pulmonary arterial hypertension was induced in rats by a single injection of monocrotaline (MCT) and recombinant human HGF (0.12 mg/day) was administered into the right ventricle cavity using osmotic pumps, which were implanted subcutaneously 21 days after MCT injection. Continuous intravenous delivery of recombinant human HGF for 14 days led to prolonged survival of animals suffering from severe MCT-induced pulmonary arterial hypertension. Although a bolus injection of recombinant human HGF did not affect pulmonary arterial pressure, a 14-day administration of recombinant human HGF attenuated the inflammatory cell infiltrate, matrix accumulation and vascular medial thickening. As a consequence, the pulmonary lumen was enlarged and the pulmonary arterial pressure was significantly reduced. Additionally, continuous administration of recombinant human HGF suppressed lung tissue expression of platelet-derived growth factor, which plays an important role in the development of pulmonary arterial hypertension. These results indicate that recombinant human HGF possibly has a great potential for improving symptoms and altering the clinical course of pulmonary arterial hypertension.
\end{abstract}

Correspondence to: Dr Akio Ido, Digestive Disease and Life-Style Related Disease, Kagoshima University Graduate School of Medical and Dental Sciences, 3-35-1 Sakuragaoka, Kagoshima 890-8520, Japan

E-mail: ido-akio@m2.kufm.kagoshima-u.ac.jp

Key words: hepatocyte growth factor, pulmonary arterial hypertension, monocrotaline, pulmonary arterial pressure, platelet-derived growth factor

\section{Introduction}

Pulmonary arterial hypertension (PAH) is a progressive, nearly always fatal condition that until recently has had very few treatment options. PAH, whether idiopathic or secondary, is characterized by dysregulated proliferation of pulmonary arterial endothelial and intimal smooth muscle cells, both resistant to cellular apoptosis, resulting in progressive pulmonary vascular remodeling and an increase in pulmonary arterial pressure (PAP) (1). Anticoagulants, diuretics, calcium channel blockers and inotropic agents have been used to treat patients with PAH, in an effort to alleviate their symptoms. Recently, specific targeted therapies using prostacyclins $(2,3)$, endothelin-receptor antagonists $(4,5)$ and phophodiesterase type 5 inhibitor (6) have been developed. However, because of the insufficient efficacy and poor tolerability of these agents $(7,8)$, new therapeutic modalities continue to be explored.

Hepatocyte growth factor (HGF) was first purified as a potent mitogen for hepatocytes from the plasma of patients with fulminant hepatic failure $(9,10)$. This protein is characterized as a broad-spectrum and multifunctional growth factor with mitogenic, motogenic, morphogenic and anti-apoptotic activities in a variety of cells (10-12). Under physiological conditions, HGF acts as an organotrophic factor, protects from tissue injury, stimulates regeneration of various organs and is now considered to be essential for wound healing and repair in injured tissues (13-16). In response to acute lung injury, HGF is involved in lung regeneration and protection $(17,18)$. Additionally, a deficiency in HGF secretion by fibroblasts in the lungs of patients with idiopathic pulmonary fibrosis and pulmonary emphysema suggests that it would have therapeutic value to increase HGF expression in their lung tissue $(19,20)$; consistent with this, HGF administration and gene therapy have been reported to ameliorate pulmonary fibrosis and emphysema in rats (21-24). Recent investigations have reported that HGF gene transfer attenuates medial hyperplasia and matrix accumulation in PAH of rats $(25,26)$.

Our research has been focused on making recombinant human HGF (rh-HGF) available as a drug. Furthermore, we have evaluated the efficacy of HGF protein-based therapy 
in various animal models $(12,15,27-29)$. Finally, we have initiated a clinical trial for the treatment of fulminant hepatic failure (30). In the present study, we have examined the effect of single or continuous injection of rh-HGF on severe PAH in rats. We demonstrate that although a single dose of rh-HGF did not reduce PAP, continuous administration of rh-HGF attenuated pulmonary arterial stenosis, resulting in a decrease in PAP and, consequently, prolonging the survival of animals with advanced PAH.

\section{Materials and methods}

Animals. Male Wister rats, six weeks of age and weighing 200-210 g, were obtained from Kyudo Co., Ltd. (Kumamoto, Japan). Rats were maintained under constant room temperature $\left(25^{\circ} \mathrm{C}\right)$ and allowed free access to a standard diet and tap water in accordance with the institutional guidelines; rats were acclimatized to these conditions for seven days before any involvement in experimental studies. The Ethics Committee of Kagoshima University (Kagoshima, Japan) approved all aspects of this study. Rats were injected subcutaneously with monocrotaline (MCT) $(40 \mathrm{mg} / \mathrm{kg})$ in order to induce PAH (Acros Organics, Geel, Belgium) (Fig. 1). Osmotic pumps (Alzet, Palo Alto, CA, USA), which deliver recombinant human HGF (0.12 mg/day) in phosphate-buffered saline (PBS) or PBS alone through catheters into the right ventricle cavity for 14 days, were implanted subcutaneously 21 days after a single MCT injection.

Hemodynamic measurements. Animals with MCT-induced PAH were anesthesized with $75 \mathrm{mg} / \mathrm{kg}$ ketamine (Daiichi Sankyo Pharma, Tokyo, Japan) and $0.5 \mathrm{mg} / \mathrm{kg}$ medetomidine (Nippon Zenyaku Kogyo Co., Fukushima, Japan). A tracheal cannula connected to a ventilator was inserted and rats were treated with artificial respiration at a frequency of 50-60 times $/ \mathrm{min}$ and a tidal volume of $5-15 \mathrm{ml} / \mathrm{kg}$. A 23-gauge cannula (A23-gauge Surflo; Terumo Co., Tokyo, Japan) was inserted into the abdominal aorta and connected to a pressure transducer (LEG-1000; Nohon Kohden Co., Tokyo, Japan) for measurement of the systolic blood pressure (BP). A 23-gauge catheter was also inserted into the pulmonary artery to measure PAP. Measurements were obtained over a 5-minute interval after waiting for the PAP and systolic BP measurement to stabilize and the means were calculated.

Histological examination and measurement of the internal area of the pulmonary artery. Lung tissues were obtained from rats with MCT-induced $\mathrm{PAH}$, which were treated with or without HGF for 14 days and stained with hematoxylin and eosin (H\&E). To evaluate the pulmonary arterial lumen, the internal and external areas of nine to ten pulmonary arteries in each rat were measured using the Microanalyzer (Nihon Poladigital, Tokyo, Japan). The percentage of the internal area of the pulmonary artery (vascular lumen ratio) was calculated using the following formula: vascular lumen ratio $(\%)=$ internal area/whole (external) area of pulmonary artery x 100.

Enzyme-linked immunosorbent assays for serum $C$-reactive protein (hs-CRP) and 6-keto prostaglandin Fl $\alpha(P G F 1 \alpha)$. Serum concentrations of hypersensitive hs-CRP and 6-keto

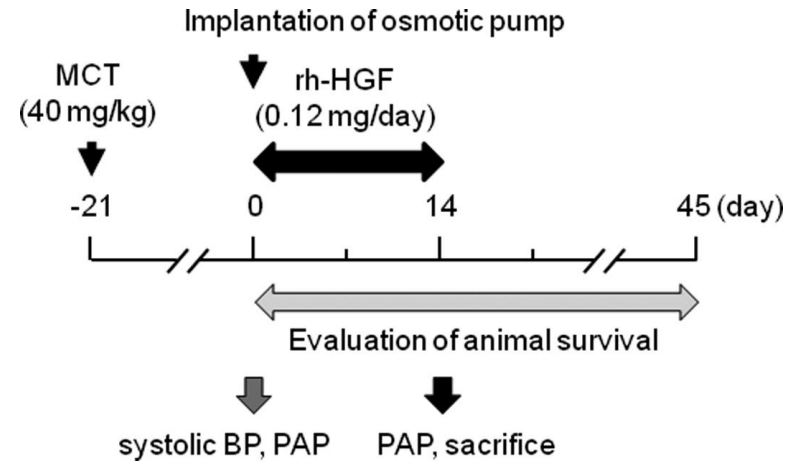

Figure 1. Summary of the study protocol. To induce pulmonary arterial hypertension (PAH), monocrotaline (MCT) $(40 \mathrm{mg} / \mathrm{kg}$ ) was subcutaneously injected 21 days before the beginning of HGF administration. Recombinant human HGF (rh-HGF) ( $0.12 \mathrm{mg} /$ day) was administered continuously for 14 days using osmotic pumps, which were implanted subcutaneously on Day 0. Survival of animals was evaluated throughout the experimental period (up to 45 days). Additionally, the effects of a bolus rh-HGF injection on systolic blood pressure (BP) and pulmonary arterial pressure (PAP) were examined on Day 0 and animals were also sacrificed for further experiments on Day 14, following PAP measurement, to evaluate the effect of continuous HGF administration.

PGF1 $\alpha$ were measured using commercially available enzyme-linked immunosorbent assay kits (Alpha Diagnostic International, San Antonio, TX, USA and GE Healthcare Bio-Sciences, Tokyo, Japan, respectively).

Real-time reverse transcription-polymerase chain reaction (RT-PCR). Total RNA was extracted from lung tissues of rats with MCT-induced PAH using Isogene (Nippon Gene, Toyama, Japan) and cDNA was synthesized from $0.5 \mu \mathrm{g}$ RNA using PrimeScript RT reagent kit (Takara, Otsu, Japan). For real-time PCR, commercially available assay mixes for tumor necrosis factor (TNF)- $\alpha$, interleukin (IL)-6, IL-12, macrophage migration inhibitory factor (MIF), fibroblast growth factor (FGF), platelet-derived growth factor (PDGF), PDGF receptor (PDGFR) and glyceraldehyde 3-phosphate dehydrogenase (GAPDH) were used to quantify mRNA levels and PCR was performed using a StepOnePlus Real-Time PCR System (Applied Biosystems, Foster City, CA). mRNA levels were normalized to GAPDH mRNA levels in the same samples.

Statistical analysis. Unless specified, data are expressed as the mean \pm SD. Statistical parameters were ascertained with Statview J-4.5 (Abacus Concepts, Inc., Berkeley, CA, USA). Differences between means were assessed by the unpaired Student's t-test. Significance level was set at $\mathrm{p}<0.05$.

\section{Results}

A single dose of $H G F$ reduced systolic $B P$, but not PAP. Intravenous injection of HGF in a bolus is known to decrease $\mathrm{BP}$ via induction of nitric oxide (NO), which is a potent vasodilator (30). Therefore, we first examined the effects of a single intravenous injection of HGF on BP and PAP in rats with PAH, which was induced by a single injection of MCT 21 days before HGF injection (Fig. 1). Systolic BP was reduced by $18.6 \pm 6.7 \mathrm{mmHg}$ just after a single intravenous HGF injec- 


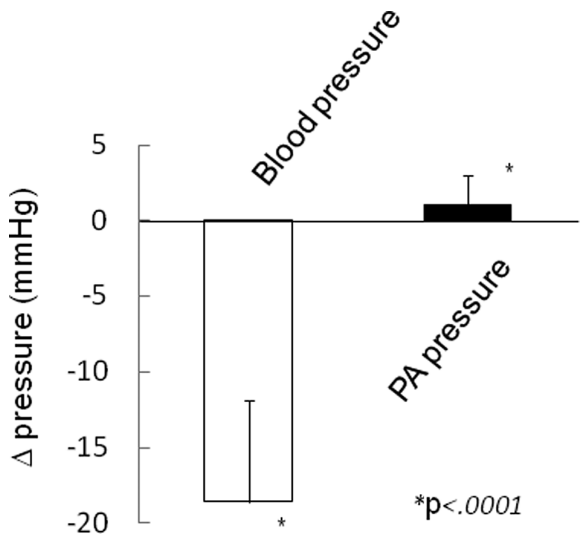

Figure 2. Single intravenous injection of HGF in a bolus reduced systolic $\mathrm{BP}$, but not PAP, in rats with PAH. Systolic BP and PAP in rats with MCT-induced PAH $(n=10)$ were measured as described in the Materials and methods. A bolus intravenous injection of HGF significantly reduced systolic BP, but not PAP. " $\mathrm{p}<0.0001$.

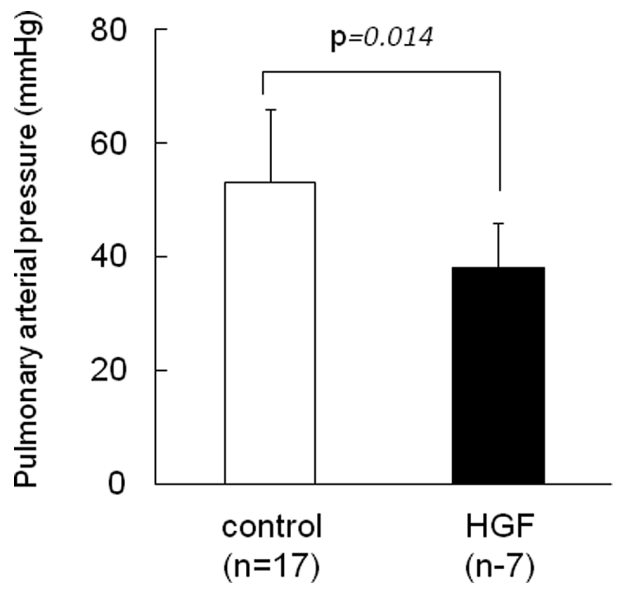

Figure 3. Continuous HGF administration reduced PAP in established PAH rats. Rats with MCT-induced PAH were treated with HGF or PBS (control) for 14 days. The systolic PAP was significantly reduced in HGF-treated rats in comparison with the control $(\mathrm{p}=0.014)$.

tion. However, PAP was not affected by a bolus injection of HGF (Fig. 2).

Continuous HGF administration reduced PAP through amelioration of pulmonary arterial stenosis in rats with $M C T$-induced PAH. To clarify the effect of continuous administration of rh-HGF on PAP, rats with PAH were catheterized and PAP was examined after 14-day HGF or PBS administration (Fig. 1). Systolic PAP was significantly reduced by HGF treatment, relative to PBS $(37.9 \pm 8.1$ vs. $53.1 \pm 12.9 \mathrm{mmHg}, \mathrm{p}=0.014$ ) (Fig. 3). Next, we evaluated the effect of HGF on MCT-induced PAH in rats by histological analysis. In control PAH rats that were treated with PBS for 14 days, inflammatory cell infiltrate, matrix accumulation and vascular medial thickness, leading to marked pulmonary arterial stenosis, were observed (Fig. 4A). In contrast, when HGF was continuously administered for 14 days, vascular medial thickness and inflammatory cell infiltrate were attenuated (Fig. 4B) and, consequently the vascular lumen ratio was significantly increased $(23.9 \pm 11.7 \%$ vs. $15.5 \pm 8.5 \%, \mathrm{p}<0.0001)$
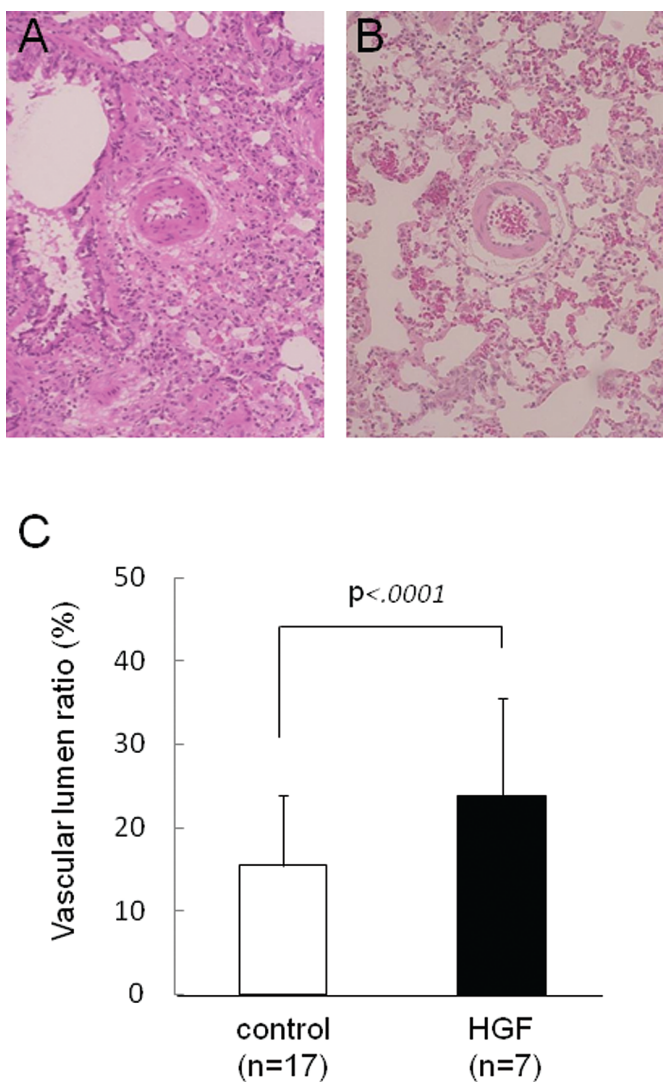

Figure 4. Treatment with HGF attenuated the pulmonary artery stenosis in rats with established PAH. (A and B) Representative photographs of lung tissues obtained from MCT-induced PAH rats, which were continuously administered PBS (A) or HGF (B) for 14 days (H\&E, x400 magnification), HGF treatment attenuated perivascular fibrosis and thickness of the arterial walls, resulting in expanded internal areas of pulmonary arteries. (C) The vascular lumen ratio of pulmonary arteries was measured as described in Materials and methods. Continuous HGF administration for 14 days significantly increased the vascular lumen ratio in rats with established PAH $(\mathrm{p}<0.0001)$.

(Fig. 4C). These results indicate that HGF ameliorated pulmonary arterial stenosis, leading to a decrease in PAP.

Treatment with $H G F$ for 14 days prolonged survival of rats with established PAH induced by MCT. Next, we examined whether HGF-induced amelioration of pulmonary arterial stenosis could improve the survival of animals with established $\mathrm{PAH}$, which was induced by a single MCT injection 21 days before HGF or PBS administration (Fig. 1). As shown in Fig. 5, all animals with MCT-induced PAH survived 14 days of treatment, whether treated with HGF or PBS alone. However, when treated with PBS alone, approximately $60 \%$ of the animals died within 30 days and none survived over 36 days. Conversely, none of the HGF-treated PAH rats died within 28 days and $80 \%$ survived the entire experimental period (up to 45 days). Intravenous injection of HGF into the right ventricle by implanted osmotic pumps significantly prolonged the survival of animals with established PAH ( $p=0.003)$.

HGF administration did not affect serum levels of either hs-CRP or 6-keto PGFla in rats with PAH. hs-CRP is a marker of minimal vascular inflammation caused by arteriosclerosis and 6-keto PGF1 $\alpha$ is a marker of potent vasodilatory 


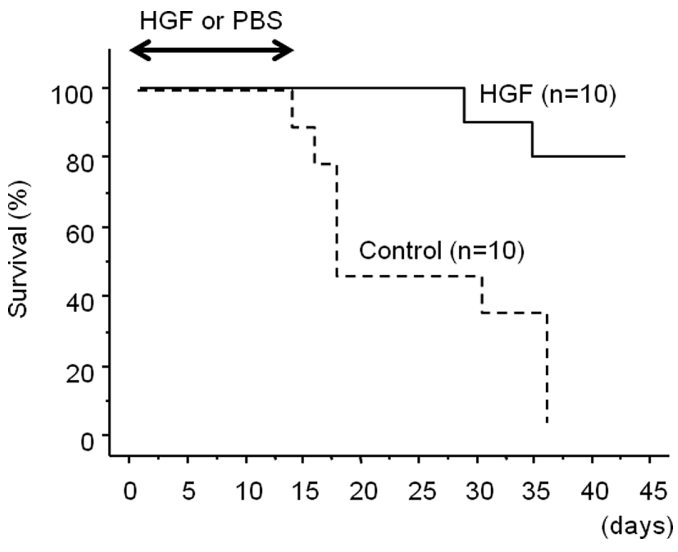

Figure 5. Administration of HGF prolonged survival of animals with MCTinduced PAH. Rats with established PAH received rh-HGF $(0.12 \mathrm{mg} /$ day $)$ (solid line) or PBS (dotted line) using implanted osmotic pumps for 14 days. Survival of animals treated with HGF was significantly longer than that of animals with PBS $(\mathrm{p}=0.003)$.

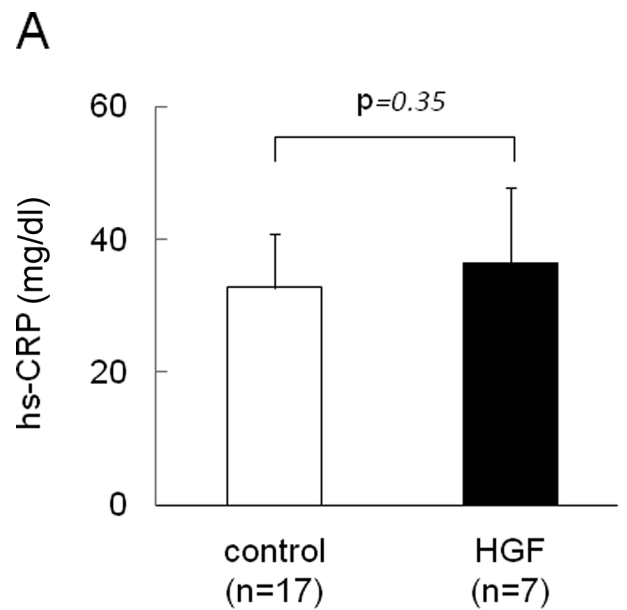

B

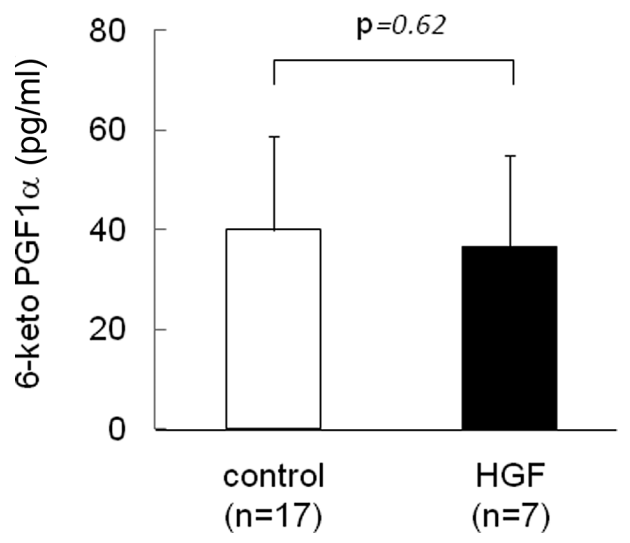

Figure 6. Serum levels of hs-CRP and 6-keto PGF1 $\alpha$ in rats with PAH were not affected by HGF administration. Serum hs-CRP and 6-keto PGF1 $\alpha$ concentration were measured by ELISA after a 14-day HGF administration as described in the Materials and methods. HGF treatment did not affected serum level of either hs-CRP or PGF1 $\alpha$ in rats with PAH.

agents. Therefore, we examined serum hs-CRP and 6-keto PGF1 $\alpha$ in PAH-rats treated with HGF or PBS alone. Treatment with HGF for 14 days did not affect either serum hs-CRP or 6-keto PGF1a (Fig. 6).
HGF treatment suppressed the expression of PDGF in lung tissues of rats with PAH. To clarify the mechanisms of HGF suppression of the development of fibrosis in rats with $\mathrm{PAH}$, we examined the effect of HGF on the mRNA expression of TNF- $\alpha$, IL-6, IL-12, MIF, FGF, PDGF and PDGFR. HGF treatment for 14 days significantly suppressed the expression of PDGF ( $p=0.026)$, one of the agents involved in development of pulmonary fibrosis leading to $\mathrm{PAH}$, in rats with MCT-induced PAH, whereas the expression of TNF- $\alpha$, IL-6, IL-12, MIF, FGF and PDGFR was not affected by this treatment (Fig. 7).

\section{Discussion}

PAH has a multifactorial pathobiology, including vasoconstriction, remodeling of the pulmonary vessel wall and thrombosis, which contributes to increased pulmonary vascular resistance in PAH. Recent investigations have reported that transfection of the lung with the HGF gene via the pulmonary artery reduces medial hyperplasia in lung arterioles and inhibits overgrowth of pulmonary artery smooth muscle cells $(25,26)$. However, there are several issues, including safety and transduction efficiency, which should be solved before clinical application of HGF gene therapy. We have developed translational medicine protocols for rh-HGF, including preparation of rh-HGF at GMP-grade, various preclinical safety tests and a clinical trial to evaluate the safety, pharmacokinetics and clinical efficacy of this compound $(32,33)$. Therefore, in the present study we investigated the efficacy of rh-HGF on pulmonary arterial stenosis, PAP and survival of rats with established PAH.

Intravenous injection of rh-HGF in a bolus has been reported to reduce the mean arterial pressure through NO (30). In this study, a single injection of rh-HGF reduced systolic BP, but did not affect PAP. Although we did not examine the effect of intravenous rh-HGF on PAP in rats without PAH, pulmonary arterial remodeling in MCT-induced PAH rats, including medial hypertrophy, intimal fibrosis and endothelial cell proliferation, may decrease the susceptibility to factors that dilate blood vessels. Conversely, continuous administration of rh-HGF for 14 days reduced thickening of the pulmonary arterial wall, resulting in enlargement of the vascular lumen and a decrease in PAP. Consequently, survival of rats with established PAH, which was induced by MCT injection 21 days before HGF treatment, was significantly prolonged. Despite the short half-life of rh-HGF in vivo (31), continuous exposure to rh-HGF has been reported to stimulate liver regeneration and proliferation and hepatic differentiation of hepatic progenitor cells $(27,28)$ and ameliorate experimental colitis (12). Repeated dose of rh-HGF also facilitated the repair of large colonic ulcers induced by 2,4,6-trinitrobenzene sulfonic acid (30) and reduced hepatic fibrosis in a rat model of liver cirrhosis (15). In addition to the finding in this study, these results indicate that the protein-based therapy of HGF is a potent therapeutic modality to treat patients with intractable diseases, including PAH, inflammatory bowel disease, hepatic failure and liver cirrhosis.

The process of pulmonary arterial remodeling involves all layers of the vessel wall. Each cell type of the pulmonary arterial wall, such as endothelial, smooth muscle and fibroblast, 

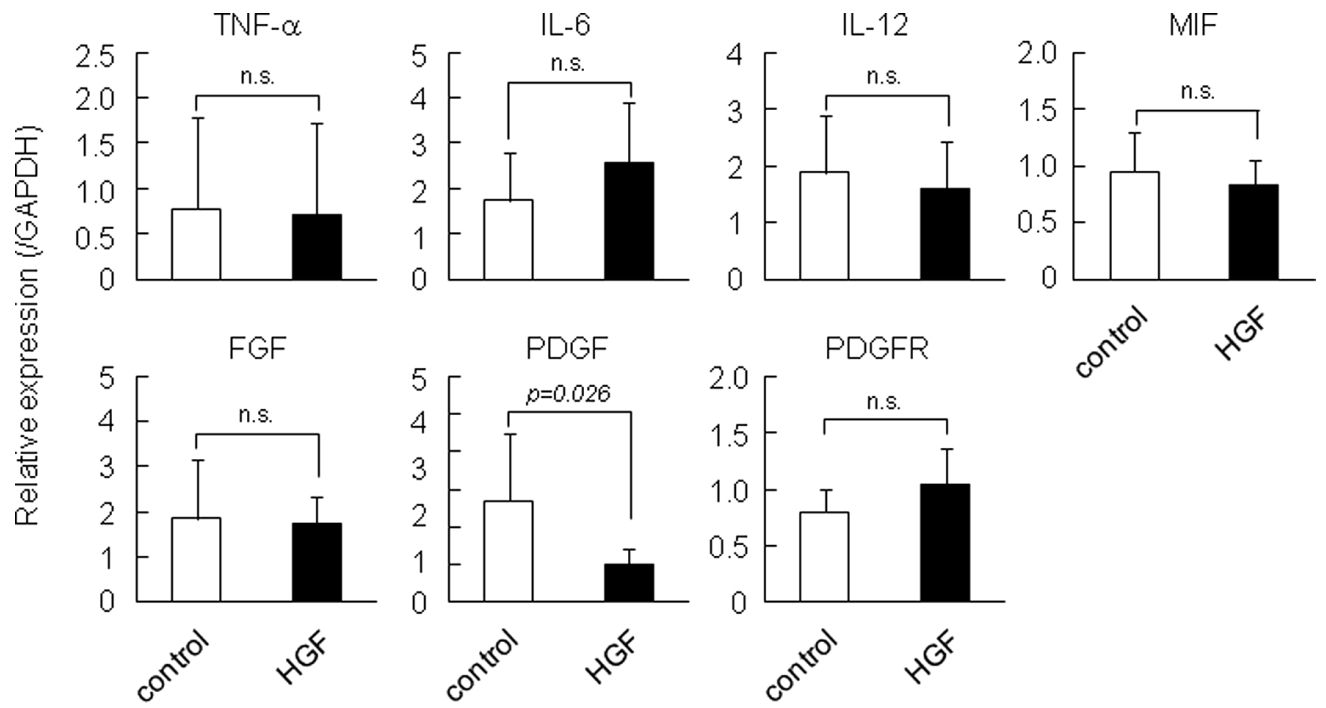

Figure 7. Treatment with HGF suppressed PDGF expression in lung tissues. Expression of TNF- $\alpha$, IL-6, IL-12, MIF, FGF, PDGF and PEGFR in lung tissues, which were obtained from HGF- or PBS (control)-treated rats with PAH, was evaluated by real-time RT-PCR. HGF administration for 14 days significantly reduced pulmonary expression of PDGF mRNA in rats with PAH $(\mathrm{p}=0.026)$.

as well as inflammatory cells and platelets, may play a significant role in PAH. During the inflammatory process of PAH, several inflammatory factors, including TNF- $\alpha$, IL-1 and IL-6, are overproduced $(7,34,35)$. Additionally, several growth factors have been implicated in the abnormal proliferation and migration of smooth muscle cells, including PDGF, basic FGF and epidermal growth factor (36-38). In vitro studies have shown that PDGF stimulates proliferation of pulmonary vascular smooth muscle cells (38). Additionally, PDGF receptor antagonists (imatinib mesylate) reverse pulmonary vascular remodeling in two different animal models of PAH (39) and results from a phase II trial of imatinib mesylate suggest that imatinib may be effective in a subset of patients with severe PAH (40). Conversely, a specific receptor for HGF, c-Met, is expressed in pulmonary arterial smooth muscle cells in MCT-induced PAH rats and HGF inhibits the proliferation of smooth muscle cells (25). In this study, administration of rh-HGF decreased the pulmonary expression of PDGF mRNA in PAH rats, whereas expression of TNF- $\alpha$, IL-6, IL-12, PDGFR and FGF was not affected by this treatment. Therefore, HGF inhibits proliferation of pulmonary arterial smooth muscle cells, leading to attenuation of pulmonary arterial stenosis, both indirectly (through decreased PDGF expression) as well as directly (through c-Met expressed in smooth muscle cells).

Increasing evidence suggests that endothelial dysfunction is a major participant in the pathogenesis of PAH. Regardless of the causes, PAH is associated with maladaptive changes in pulmonary vascular structure and function. When apoptosis is induced in pulmonary arterial endothelial cells, some factors that generate apoptosis-resistant proliferative endothelial cells and induce vascular smooth muscle cell proliferation are released from the apoptotic endothelial cells (41). Pulmonary vasoconstriction and vascular smooth muscle cell proliferation are strongly linked to endothelial cell dysfunction (42). It is now understood that the remodeling process involves all the components of the pulmonary vascular walls (35). Since normal pulmonary arterial endothelial cells express c-Met and HGF suppresses apoptosis in endothelial cells (25), HGF may block the initial step of PAH development (endothelial dysfunction), in addition to inhibiting overgrowth of pulmonary arterial smooth muscle cells.

rh-HGF is now available as a therapeutic agent to treat patients. A phase I/IIa clinical trial for patients with acute liver failure is already underway (31). Although the safety of rh-HGF should be carefully evaluated in humans, HGF gene therapy has been reported to enhance the ameliorating effect of prostacyclin for PAH rats (26). Therefore, the beneficial effect of HGF protein-based therapy in PAH models described herein sheds light on the development of new therapeutic modalities aimed at treating patients with severe PAH.

\section{Acknowledgements}

We thank Ms. Yuko Morinaga and Kaoru Yoshimitsu for technical and secretarial assistance, respectively. This study was supported by a Grant-in-Aid from the Ministry of Education, Culture, Sports, Science and Technology (19209028).

\section{References}

1. Barst RJ, McGoon M, Torbicki A, Sitbon O, Krowka MJ, Olschewski $\mathrm{H}$ and Gaine S: Diagnosis and differential assessment of pulmonary arterial hypertension. J Am Coll Cardiol 43 (12 Suppl. S): 40S-47S, 2004.

2. Sitbon O, Humbert M, Nunes H, Parent F, Garcia G, Hervé P, Rainisio $M$ and Simonneau G: Long-term intravenous epoprostenol in primary pulmonary hypertension: prognostic factors and survival. J Am Coll Cardiol 40: 780-788, 2002.

3. Barst RJ, McGoon M, McLaughlin V, Tapson V, Rich S, Rubin L, Wasserman K, Oudiz R, Shapiro S, Robbins IM, Channick R, Badesch D, Rayburn BK, Flinchbaugh R, Sigman J, Arneson C and Jeffs R: Beraprost Study Group: Beraprost therapy for pulmonary arterial hypertension. J Am Coll Cardiol 41: 2119-2125, 2003.

4. Humbert M, Segal ES, Kiely DG, Carlsen J, Schwierin B and Hoeper MM: Results of European post-marketing surveillance of bosentan in pulmonary hypertension. Eur Respir J 30: 338-344, 2007. 
5. Galiè N, Beghetti M, Gatzoulis MA, Granton J, Berger RM, Lauer A, Chiossi E and Landzberg M; Bosentan Randomized Trial of Endothelin Antagonist Therapy-5 (BREATHE-5) Investigators: Besentan therapy in patients with Eisenmenger syndrome: a multicenter, double-blind, randomized, placebocontrolled study. Circulation 114: 48-54, 2006.

6. Croom KF and Curran MP: Sildenafil: a review of its use in pulmonary arterial hypertension. Drugs 68: 383-397, 2008.

7. Humbert M, Sitbon O and Simonneau G: Treatment of pulmonary arterial hypertension. New Engl J Med 351: 1425-1436, 2004

8. Channick RN, Simonneau G, Sitbon O, Robbins IM, Frost A, Tapson VF, Badesch DB, Roux S, Rainisio M, Bodin F and Rubin LJ: Effects of the dual endothelin-receptor antagonist bosentan in patients with pulmonary hypertension: a randomized placebo-controlled study. Lancet 358: 1119-1123, 2001.

9. Gohda E, Tsubouchi H, Nakayama H, Hirono S, Takahashi K, Koura M, Hashimoto S and Daikuhara Y: Human hepatocyte growth factor in plasma from patients with fulminant hepatic failure. Exp Cell Res 166: 139-150, 1986.

10. Gohda E, Tsubouchi H, Nakayama H, Hirono S, Sakiyama O, Takahashi K, Miyazaki H, Hashimoto S and Daikuhara Y: Purification and partial characterization of hepatocyte growth factor from plasma of a patient with fulminant hepatic failure. J Clin Invest 81: 414-419, 1988.

11. Igawa T, Kanda S, Kanetake H, Saitoh Y, Ichihara A and Tomita Y: Hepatocyte growth factor is a potent mitogen for cultured rabbit renal tubular epithelial cells. Biochem Biophys Res Commun 174: 831-838, 1991.

12. Tahara Y, Ido A, Yamamoto S, Miyata Y, Uto H, Hori T, Hayashi $\mathrm{K}$ and Tsubouchi $\mathrm{H}$ : Hepatocyte growth factor facilitates colonic mucosal repair in experimental ulcerative colitis in rats. J Pharmacol Exp Ther 307: 146-151, 2003.

13. Nakamura T, Mizuno S, Matsumoto K, Sawa Y, Matsuda $H$ and Nakamura T: Myocardial protection from ischemia/reperfusion injury by endogenous and exogenous HGF. J Clin Invest 106: $1511-1519,2000$

14. Ido A, Numata M, Kodama M and Tsubouchi H: Mucosal repair and growth factors: recombinant human hepatocyte growth factor as an innovative therapy for inflammatory bowel disease. J Gastroenterol 40: 925-931, 2005.

15. Kusumoto K, Ido A, Moriuchi A, Katsura T, Kim ID, Takahama Y, Numata M, Kodama M, Hasuike S, Nagata K, Uto H, Inui K and Tsubouchi H: Repeated intravenous injection of recombinant human hepatocyte growth factor ameliorates liver cirrhosis but causes albuminuria in rats. Int J Mol Med 17: 503-509, 2006.

16. Homsi E, Janino P, Amano M, Saraiva and Camara NO: Endogenous hepatocyte growth factor attenuates inflammatory response in glycerol-induced acute kidney injury. Am J Nephrol 29: 283-291, 2009

17. Yanagita K, Matsumoto K, Sekiguchi K, Ishibashi H, Niho Y and Nakamura T: Hepatocyte growth factor may act as a pulmotorophic factor on lung regeneration after acute lung injury. $\mathrm{J}$ Biol Chem 268: 21212-21217, 1993.

18. Yamada T, Hisanaga M, Nakajima Y, Mizuno S, Matsumoto K Nakamura $\mathrm{T}$ and Nakano $\mathrm{H}$ : Enhanced expression of hepatocyte growth factor by pulmonary ischemia-reperfusion injury in the rat. Am J Respir Crit Care Med 162: 707-715, 2000.

19. Marchand-Adam S, Fabre A, Mailleux AA, Marchal J, Quesnel C, Kataoka H, Aubier M, Dehoux M, Soler P and Crestani B: Defect of hepatocyte growth factor secretion by fibroblasts in idiopathic pulmonary fibrosis. Am J Respir Crit Care Med 168: 1156-1161, 2003.

20. Plantier L, Marchand-Adam S, Marchal-Sommé J, Lesèche G, Fournier M, Dehoux M, Aubier M and Crestani B: Defect of hepatocyte growth factor production by fibroblasts in human pulmonary emphysema. Am J Physiol Lung Cell Mol Physiol 288: L641-L647, 2005.

21. Yaekashiwa M, Nakayama $S$, Ohnuma $K$, Sakai T, Abe T, Satoh K, Matsumoto K, Nakamura T, Takahashi T and Nukiwa T: Simultaneous or delayed administration of hepatocyte growth factor equally represses the fibrotic changes in murine lung injury incued by bleomycin. A morphologic study. Am J Respir Crit Care Med 156: 1937-1944, 1997.

22. Watanabe M, Ebina M, Orson FM, Nakamura A, Kubota K, Koinuma D, Akiyama K, Maemondo M, Okouchi S, Tahara M, Matsumoto K, Nakamura T and Nukiwa T: Hepatocyte growth factor gene transfer to alveolar septa for effective suppression of lung fibrosis. Mol Ther 12: 58-67, 2005.
23. Shigemura N, Sawa Y, Mizuno S, Ono M, Ohta M, Nakamura T, Kaneda $\mathrm{Y}$ and Matsuda H: Amelioration of pulmonary emphysema by in vivo gene transfection with hepatocyte growth factor in rats. Circulation 111: 1407-1414, 2005.

24. Gazdhar A, Fachinger P, van Leer C, Pierog J, Gugger M, Friis R, Schmid RA and Geiser T: Gene transfer of hepatocyte growth factor by electroporation induces bleomycin-induced lung fibrosis. Am J Physiol Lung Cell Mol Physiol 292: L529-L536, 2007.

25. Ono M, Sawa Y, Mizuno S, Fukushima N, Ichikawa H, Bessho K, Nakamura T and Matsuda H: Hepatocyte growth factor suppresses vascular medial hyperplasia and matrix accumulation in advanced pulmonary hypertension of rats. Circulation 110: 2896-2902, 2004.

26. Ono M, Sawa Y, Fukushima N, Suhara H, Nakamura T, Yokoyama C, Tanabe T and Matsuda T: Gene transfer of hepatocyte growth factor with prostacyclin synthase in severe pulmonary hypertension of rats. Eur J Cardiothorac Surg 26: 1092-1097, 2004

27. Ishii T, Sato M, Sudo K, Suzuki M, Nakai H, Hishida T, Niwa T, Umezu K and Yuasa S: Hepatocyte growth factor stimulates liver regeneration and elevates blood protein level in normal and partially hepatectomized rats. J Biochem 117: 1105-1112, 1995.

28. Hasuike S, Ido A, Uto H, Moriuchi A, Tahara Y, Numata M, Nagata K, Hori T, Hayashi K and Tsubouchi H: Hepatocyte growth factor accelerates the proliferation of hepatic oval cells and possibly promotes the differentiation in a 2-acethyaminofluorene/partial hepatectomy model in rats. J Gastroenterol Hepatol 20: 1753-1761, 2005.

29. Sato M, Kakubari M, Kawamura M, Sugimoto J, Matsumoto K and Ishii T: The decrease in total collagen fibers in the liver by hepatocyte growth factor after formation of cirrhosis induced by thioacetamide. Biochem Pharmacol 59: 681-690, 2000.

30. Numata M, Ido A, Moriuchi A, Kim ID, Tahara Y, Yamamoto S, Hasuike S, Nagata K, Miyata Y, Uto $\mathrm{H}$ and Tsubouchi $\mathrm{H}$ : Hepatocyte growth factor facilitates the repair of large colonic ulcers in 2,4,6-trinitrobenzene sulfonic acid-induced colitis in rats. Inflamm Bowel Dis 11: 551-558, 2005.

31. Ido A and Tsubouchi H: Translational research to identify clinical applications of hepatocyte growth factor. Hepatol Res 39: 739-747, 2009.

32. Yang R, Bunting S, Ko A, Schwall R and Jin H: Hemodynamic effects of scatter factor in conscious rats. J Cardiovasc Pharmacol 30: 294-301, 1997

33. Ido A, Moriuchi A, Kim ID, Numata M, Nagata-Tsubouchi Y, Hasuike S, Uto $\mathrm{H}$ and Tsubouchi $\mathrm{H}$ : Pharmacokinetic study of recombinant human hepatocyte growth factor administered in a bolus intravenously or via portal vein. Hepatol Res 30: 175-181, 2004.

34. Dorfmuller P, Perros F, Balabanian K and Humbert $\mathrm{M}$ Inflammation in pulmonary arterial hypertension. Eur Respir $\mathrm{J}$ 22: 358-363, 2003

35. Farber HW and Loscalzo J: Pulmonary arterial hypertension New Engl J Med 351: 1655-1665, 2004.

36. Ushio-Fukai M, Griendling KK, Becker PL, Hilenski L, Halleran S and Alexander RW: Epidermal growth factor receptor transactivation by angiotensin II receptor requires reactive oxygen species in vascular smooth muscle cells. Arterioscler Thromb Vasc Biol 21: 489-495, 2001.

37. Xin X, Johnson AD, Scott-Burden T, Engler D and Casscells W: The predominant form of fibroblast growth factor receptor expressed by proliferating human arterial smooth muscle cells in culture in type I. Biochem Biophys Res Commun 204: 557-564, 1994.

38. Yu Y, Sweeney M, Zhang S, Platoshyn O, Landsberg J, Rothman A and Yuan JX: PDGF stimulates pulmonary vascular smooth muscle cell proliferation by upregulating TRPC6 expression. Am J Physiol Cell Physiol 284: C316-C330, 2003

39. Schermuly RT, Dony E, Ghofrani HA, Pullamsetti S, Savai R, Roth M, Sydykov A, Lai YJ, Weissmann N, Seeger W and Grimminger F: Reversal of experimental pulmonary hypertension by PDGF inhibition. J Clin Invest 115: 2811-2821, 2005.

40. Chhina MK, Nargues W, Grant GM and Nathan SD: Evaluation of imatinib mesylate in the treatment of pulmonary arterial hypertension. Future Cardiol 6: 19-35, 2010.

41. Sakao S, Tatsumi K and Voelkel NF: Endothelial cells and pulmonary arterial hypertension: apoptosis, proliferation, interaction and transdifferentiation. Respir Res 10: 95, 2009.

42. Perros F, Dorfmüller P and Humbert M: Current insights on the pathogenesis of pulmonary arterial hypertension. Semin Respir Crit Care Med 26: 355-364, 2005. 